\title{
Componentes produtivos do milho sob diferentes manejos de plantas daninhas e arranjos de plantio em sistema agrossilvipastoril
}

\author{
Productive components of maize under different weed management \\ systems and planting arrangements in agrosilvopasture system
}

\author{
Márcia Vitória Santos ${ }^{\mathrm{I}}$ Daniel Valadão Silva ${ }^{\mathrm{II}}$ Dilermando Miranda da Fonseca ${ }^{\mathrm{II}}$ \\ Marcelo Rodrigues dos Reis ${ }^{\text {II }}$ Lino Roberto Ferreira ${ }^{\text {III }}$ \\ Sílvio Nolasco de Oliveira Neto ${ }^{\mathrm{III}}$ Fabiana Lopes Ramos de Oliveira ${ }^{\mathrm{II}}$
}

RESUMO

O sucesso de um cultivo consorciado esta relacionado com o conhecimento de todos os fatores que afetam o crescimento e produção das espécies. Objetivou-se neste trabalho avaliar a produção de grãos de milho sob diferentes manejos de plantas daninhas e arranjos de plantio em sistema agrossilvipastoril. $O$ delineamento experimental foi em blocos casualizados, com três repetições. Os tratamentos foram dispostos no esquema de parcelas subdivididas, sendo as parcelas correspondentes aos sistemas de consórcio: eucalipto ou eucalipto junto com acácia consorciada com milho e Brachiaria brizantha $c v$. 'Marandu' ou B. decumbens $c v$. 'Basilisk' ou B. brizantha $c v$. 'Piatã'. Nas subparcelas, alocaram-se os sistemas de manejo de plantas daninhas: atrazine aplicado isoladamente ou mistura em tanque do atrazine com subdose do nicosulfuron. Adicionaram-se duas testemunhas relativas ao milho em monocultivo nos dois sistemas de manejos de plantas daninhas. As espécies florestais foram transplantadas na ocasião da semeadura do milho e das braquiárias, realizada em plantio direto. A aplicação de nicosulfuron em mistura com atrazine promoveu o aumento da altura de plantas e inserção de espigas, sem influenciar na produtividade de grãos de milho. O eucalipto, acácia e as espécies de braquiárias, estabelecidos concomitantemente, não influenciaram na produtividade de milho. A produtividade de grãos de milho é reduzida no sistema agrossilvipastoril em relação ao monocultivo.

Palavras-chave: Brachiaria brizantha (Syn.Urochloa brizantha), Brachiaria decumbens (Syn. Urochloa decumbens), Acacia mangium, pastagem degradada.

\section{ABSTRACT}

The success of an intercropping system is related to the knowledge of all factors that affect their growth and species production. The aim of this study was to evaluate the grain corn production under different weed management systems and planting arrangements in agrosylvopastoral system. The experimental design was a randomized complete block design with three replications. The treatments were arranged in split plots, with the corresponding portions of intercropping systems: eucalyptus or acacia eucalyptus intercropping with maize and Brachiaria brizantha $c v$. 'Marandu' or B. decumbens $c v$. 'Basilisk' or Brachiaria brizantha $c v$. 'Piatã'. In the sub-plots allocated there were systems of weed management: atrazine applied alone or in mixture with atrazine tank with nicosulfuron sub-dose. It was added up two control groups for maize monoculture in both systems of weed management systems. Forest species were transplanted at planting corn time and brachiaria held on till. The application of nicosulfuron and atrazine mixture promoted the increase in plant height and ear insertion without affecting the maize grain yield. Eucalyptus, Acacia and species of Brachiaria, established concomitantly, had no effect on corn yield. The corn grain yield is reduced in agrosylvopastoral system compared to monoculture.

Key words: Brachiaria brizantha (Syn. Urochloa brizantha), Brachiaria decumbens (Syn. Urochloa decumbens), Acacia mangium, degraded pasture.

\section{INTRODUÇÃO}

A associação de espécies em sistemas integrados, juntamente com a utilização de práticas conservacionistas, como a adoção do sistema de plantio direto, desponta como opção na recuperação de pastagens degradadas e na produção de madeira, sem deixar de lado as demais atividades agrícolas tradicionalmente. Nos sistemas agrossilvipastoris, espécies lenhosas são utilizadas em associações com cultivos agrícolas, pastagens e, ou, animais na mesma área, de forma simultânea

\footnotetext{
IDepartamento de Zootecnia, Universidade Federal dos Vales do Jequitinhonha e Mucuri (UFVJM), Diamantina, MG, Brasil.

"Departamento de Ciências Agrárias, Universidade Federal de Viçosa (UFV), Campus Rio Paranaíba, 38810-000, Rio Paranaíba, MG, Brasil. E-mail: danielvaldaos@yahoo.com.br. *Autor para correspondência.

IIIUFV, Viçosa, MG, Brasil.
} 
ou sequencial, otimizando a terra e a rentabilidade do empreendimento (MACEDO et al., 2006).

O sucesso de um sistema consorciado depende do correto manejo das espécies e dos fatores de produção de afetam as espécies, visando a garantir retornos econômicos e ambientais satisfatórios (MELOTTO et al, 2009). Dentre os principais fatores limitantes da produção de sistemas consorciados, destacamse as plantas daninhas (FERREIRA et al., 2007). A interferência das plantas daninhas sobre as espécies consorciadas pode limitar sua produção, sobretudo nos estádios iniciais de crescimento das culturas (SILVA et al., 2014).

Além das plantas daninhas, as espécies consorciadas em um sistema agrossilvipastoril estão propensas a interferência das demais culturas consortes. No caso do milho em consórcio com uma espécie arbórea e outra forrageira, o sombreamento da primeira e a competição pelos recursos do solo da segunda podem afetar diretamente o crescimento e desenvolvimento do milho. Todavia, essa interferência é dependente das cultivares utilizadas e do manejo empregado (FREITAS et al., 2008; GIMENES et al., 2008). Dessa maneira, estudos que elucidem os efeitos das espécies em consórcio podem auxiliar na definição de estratégias que visem a beneficiar a espécie no momento oportuno.

No consórcio do milho com forrageiras, a aplicação da mistura do atrazine com subdoses de nicosulfuron tem proporcionado bom controle das plantas daninhas, sem comprometer a formação do pasto após a colheita do milho (JAKELAITIS et al., 2004; FREITAS et al., 2005). Neste caso, o uso do nicossulfuron visa a retardar o crescimento da forrageira, de modo a não interferir no crescimento do milho. Porém, inexistem informações a respeito dessa eficiência em sistemas consorciados mais complexos, como o agrossilvipastoris.

O conhecimento da forma como a forrageira, a cultura anual e as árvores são afetadas em um consórcio é de fundamental importância para que haja êxito na formação e, ou, na renovação de pastagens e produção satisfatória das culturas. Todavia, são escassos estudos sobre arranjos de plantio e a influência de manejos de plantas daninhas em relação aos demais componentes em sistemas agrossilvipastoris. Dessa forma, objetivou-se avaliar a produção de grãos de milho em função do manejo de plantas daninhas e arranjos de plantio em sistema agrossilvipastoril.

\section{MATERIAL E MÉTODOS}

O experimento foi realizado em pasto degradado de capim-gordura (Melinis minutiflora), localizado no município de Viçosa, Minas Gerais $\left(20^{\circ} 45^{\prime} \mathrm{S} ; 42^{\circ} 51^{\prime} \mathrm{W} ; 651 \mathrm{~m}\right)$. O solo da área experimental foi um Latossolo Vermelho-Amarelo, de textura argilosa e com relevo medianamente ondulado, com as seguintes características químicas: $\mathrm{pH}$ em $\mathrm{H}_{2} \mathrm{O}: 5,60 ; \mathrm{P}: 1,13 \mathrm{mg} \mathrm{dm}^{-3}$ (Mehlich) e $\mathrm{K}: 41,00 \mathrm{mg} \mathrm{dm}{ }^{-3} ; \mathrm{Ca}^{+2}: 3,33 ; \mathrm{Mg}^{+2}$ : $0,57 \mathrm{e} \mathrm{Al}^{+3}: 0,03 \mathrm{cmol}_{\mathrm{c}} \mathrm{dm}^{-3}\left(\mathrm{KCl} 1 \mathrm{~mol} \mathrm{~L}^{-1}\right), \mathrm{CTC}$ (T): $5,99 \mathrm{cmol}_{\mathrm{c}} \mathrm{dm}^{-3}$, soma de bases: $2,34 \mathrm{cmol}_{\mathrm{c}}$ $\mathrm{dm}^{-3}, \mathrm{H}+\mathrm{Al}^{\mathrm{c}}: 3,65 \mathrm{cmol}_{\mathrm{c}} \mathrm{dm}^{-3}$ e $2,37 \mathrm{dag} \mathrm{kg}^{-1}$ de matéria orgânica e $20,35 \mathrm{mg} \mathrm{dm}^{-3}$ de P-rem.

Para o preparo da área, realizou-se a roçada do pasto em setembro de 2007 e dois meses depois a dessecação da vegetação na área com a aplicação de $1,8 \mathrm{~kg} \mathrm{ha}^{-1}$ de glyphosate e $0,480 \mathrm{~kg} \mathrm{ha}^{-1}$ de $2,4-$ D. Decorrida uma semana da dessecação, realizouse a calagem do solo, aplicando-se $1.000 \mathrm{~kg} \mathrm{ha}^{-1} \mathrm{de}$ calcário com PRNT de $82 \%$, distribuído a lanço na superfície do solo.

As semeaduras do milho híbrido duplo (DKB 747) e das forrageiras foram realizadas em dezembro de 2007 no sistema de plantio direto. O espaçamento do milho foi de $0,8 \mathrm{~m}$ entre fileiras e das forrageiras de $0,4 \mathrm{~m}$, sendo estas semeadas na linha e uma linha na entrelinha do milho. Utilizouse na semeadura $4 \mathrm{~kg} \mathrm{ha}^{-1}$ de sementes puras viáveis para cada espécie forrageira e seis sementes por metro linear de milho. Nas parcelas em consórcio, a semeadura do milho e das braquiárias foi distanciada $1,5 \mathrm{~m}$ das fileiras de árvores. As mudas de eucalipto, clone 3336 de Eucalyptus grandis x E. urophylla (eucalipto) e de Acacia mangium (acácia) foram plantadas em covas de 0,40x0,40x0,40m, no espaçamento de $12 \mathrm{~m}$ entre fileiras e $2 \mathrm{~m}$ entre plantas, na mesma ocasião da semeadura do milho e das forrageiras. Nos tratamentos com acácia, estas foram plantadas alternadas ao eucalipto, na linha de plantio.

O delineamento utilizado foi de blocos casualizados, com três repetições. Os tratamentos foram dispostos no esquema de parcelas subdivididas, sendo que as parcelas corresponderam aos diferentes sistemas de consórcio: eucalipto + milho + Brachiaria brizantha cv. 'Marandu'; eucalipto + milho $+\boldsymbol{B}$. decumbens cv. 'Basilisk'; eucalipto + milho $+\boldsymbol{B}$. brizantha cv. 'Piatã'; eucalipto + acácia + milho $+\boldsymbol{B}$. brizantha cv. 'Marandu'; eucalipto + acácia + milho $+\boldsymbol{B}$. decumbens cv. 'Basilisk'; eucalipto + acácia + milho + B. brizantha cv. 'Piatã'. Nas subparcelas, alocaramse os sistemas de manejo de plantas daninhas: $1,5 \mathrm{~kg}$ 
$\mathrm{ha}^{-1}$ de atrazine aplicado isoladamente; mistura em tanque de $1,5 \mathrm{~kg} \mathrm{ha}^{-1}$ de atrazine com $0,006 \mathrm{~kg} \mathrm{ha}^{-1} \mathrm{de}$ nicosulfuron. Além disso, foram adicionadas mais duas testemunhas relativas ao milho em monocultivo nos dois sistemas de manejos de plantas daninhas.

Cada unidade amostral dos tratamentos em consórcio apresentou dimensões de $24 \mathrm{~m}$ de largura por $12 \mathrm{~m}$ de comprimento, totalizando uma área de $288 \mathrm{~m}^{2}$, composta por três fileiras de eucalipto ou eucalipto + acácia, espaçadas a cada $12 \mathrm{~m}$. O milho e as espécies forrageiras foram cultivados entre as fileiras das espécies arbóreas. Nas parcelas em monocultivo de milho, as dimensões eram de $24 \mathrm{~m}$ de largura por $10 \mathrm{~m}$ de comprimento, totalizando uma área de $240 \mathrm{~m}^{2}$.

$\mathrm{Na}$ adubação do milho, foram aplicados $400 \mathrm{~kg} \mathrm{ha}^{-1}$ da fórmula 8-28-16 (N-P-K) na semeadura e $100 \mathrm{~kg} \mathrm{ha}^{-1}$ de nitrogênio em cobertura (ureia). Para adubação das espécies arbóreas, foram utilizados no plantio $300 \mathrm{~g}$ de fosfato reativo por cova. Aos 25 dias após transplantio das mudas, realizou-se a adubação com N-P-K, utilizando $200 \mathrm{~g}$ da fórmula 8-28-16 por cova, distribuída em duas covetas ao lado de cada muda. Após 60 dias do transplantio, procedeuse à adubação de manutenção, aplicando-se $125 \mathrm{~g}$ de cloreto de potássio $+50 \mathrm{~g}$ de sulfato de amônio e $10 \mathrm{~g}$ de bórax $+5 \mathrm{~g}$ de sulfato de zinco por planta.

Os herbicidas nicosulfuron e atrazine foram aplicados no milho 22 dias após a emergência das plantas, ocasião em que as plantas daninhas dicotiledôneas e as monocotiledôneas, bem como as forrageiras, apresentavam em média duas folhas totalmente expandidas. Esses herbicidas foram aplicados em área total sobre as culturas de milho $\mathrm{e}$ braquiária, deixando-se uma faixa de $1,0 \mathrm{~m}$ de cada linha das espécies florestais sem aplicação. Utilizouse pulverizador costal, com pressão constante mantida por $\mathrm{CO}_{2}$, munido com ponta de pulverização TT11002 e válvula reguladora de pressão (Jacto) de $300 \mathrm{kPa}$, calibrado para $80 \mathrm{~L} \mathrm{ha}^{-1}$ de calda. O controle de plantas daninhas na linha das espécies florestais foi realizado, sempre que necessário, com o herbicida glyphosate.

A colheita de milho para grãos foi realizada aos 130 dias após o plantio. Em cada parcela, foi realizada amostragem de $4 \mathrm{~m}$ de comprimento de milho nas duas fileiras centrais (totalizando $8 \mathrm{~m}$ ) para avaliação do número de espigas por planta, altura de planta e altura de inserção de espiga. A produtividade de grãos de milho, nas parcelas em consórcio, foi avaliada em $4 \mathrm{~m}$ de comprimento nas duas fileiras centrais e nas duas fileiras laterais adjacentes às linhas de cultivo das espécies arbóreas. Nas parcelas em monocultivo, avaliou-se $8 \mathrm{~m}$ lineares nas fileiras centrais de cada parcela para estimar a produtividade, corrigiu-se a umidade dos grãos para $13 \%$. O estante de plantas foi realizado pela contagem de todas as plantas de milho na parcela.

Todos os dados foram submetidos ao teste de normalidade de Shapiro-Wilk e à análise de variância. As médias das características do milho nos diferentes manejos de planta daninha, consorciado e sem consorciação, e da interação entre elas, foram comparadas pelo teste de Tukey a $5 \%$ de probabilidade.

\section{RESULTADOS E DISCUSSÃO}

Constatou-se interação significativa $(\mathrm{P}<0,05)$ entre os arranjos de plantas no sistema agrossilvipastoril e os manejos de plantas daninhas sendo então desdobrado para estudo. $\mathrm{O}$ milho cultivado em monocultivo apresentou estande final de plantas de milho maior em relação aos arranjos de plantio no sistema agrossilvipastoril, independente do método de controle (Tabela 1). Vale ressaltar que foi utilizado, no cálculo do estande, o número de plantas em toda parcela. Dessa maneira, enquanto o milho em monocultivo apresentava plantas em toda a parcela, a cultura semeada nas entrelinhas das árvores tinha uma redução de aproximadamente $25 \%$ da área efetiva, devido à presença do componente arbóreo. Resultados semelhantes foram obtidos por MACEDO et al. (2006), em cultivo consorciado do milho com clones de eucalipto com 24 meses plantados no espaçamento $10 \times 4 \mathrm{~m}$.

O manejo de plantas daninhas não proporcionou diferenças no estande final de plantas de milho de cada sistema (Tabela 2). Além da efetividade do uso do herbicida, a supressão de plantas daninhas causada pelas plantas de braquiaria, cultivadas na linha e entre-linhas do milho, também colaborou para tais resultados. $\mathrm{O}$ mesmo fato foi relatado por SEVERINO et al. (2006, a e b).

A altura de plantas e a altura de inserção de espiga do milho foram influenciadas pelos manejos de plantas daninhas (Tabela 1). A adição do nicosulfuron ao atrazine favoreceu o crescimento das plantas de milho e a altura de inserção das espigas, em relação às plantas que foram submetidas apenas à aplicação da atrazine, exceto para milho em monocultivo, cujas diferenças não foram significativas, demonstrando que as braquiárias tiveram sua competição reduzida com a aplicação do nicosulfuron, devido ao efeito da toxidez causada por este herbicida (JAKELAITIS et al., 2005).

O nicosulfuron é recomendado para controle de poáceas e algumas dicotiledôneas e para a supressão da braquiária em sistemas de consórcio dessa forrageira com o milho (PETTER et al., 2011; 
Tabela 1 - Estande, altura e inserção de espigas de plantas de milho sob diferentes manejos de plantas daninhas e arranjos de plantio entre a cultura anual, forrageiras e espécies arbóreas.

\begin{tabular}{|c|c|c|c|c|c|c|}
\hline \multirow{2}{*}{ Arranjo de Plantio } & \multicolumn{2}{|c|}{---- Estande (plantas ha-1) ---- } & \multicolumn{4}{|c|}{---- Alturas de plantas (m) ----- ---- Inserção de espigas $(\mathrm{m})$---- } \\
\hline & Atrazine & Atr + Nic. & Atrazine & Atr + Nic. & Atrazine & Atr + Nic. \\
\hline Milho + 'Marandu' + eucalipto & $49.219 \mathrm{Ba}$ & $53.906 \mathrm{Ba}$ & $2,16 \mathrm{Bb}$ & $2,27 \mathrm{Aa}$ & $1,16 \mathrm{Cb}$ & $1,23 \mathrm{Aa}$ \\
\hline Milho + 'Marandu' + eucalipto+acácia & $50.391 \mathrm{Ba}$ & $53.906 \mathrm{Ba}$ & $2,17 \mathrm{Bb}$ & $2,25 \mathrm{Aa}$ & $1,17 \mathrm{BCb}$ & $1,22 \mathrm{Aa}$ \\
\hline Milho + 'Basilisk' + eucalipto & $52.734 \mathrm{Ba}$ & $56.250 \mathrm{Ba}$ & $2,23 \mathrm{ABb}$ & $2,31 \mathrm{Aa}$ & $1,21 \mathrm{ABCb}$ & $1,25 \mathrm{Aa}$ \\
\hline Milho + 'Basilisk' + eucalipto + acácia & $52.734 \mathrm{Ba}$ & $56.250 \mathrm{Ba}$ & $2,23 \mathrm{ABb}$ & $2,30 \mathrm{Aa}$ & $1,21 \mathrm{ABb}$ & $1,25 \mathrm{Aa}$ \\
\hline Milho + 'Piatã' + eucalipto & $51.563 \mathrm{Ba}$ & $55.078 \mathrm{Ba}$ & $2,18 \mathrm{Bb}$ & $2,27 \mathrm{Aa}$ & $1,17 \mathrm{BCb}$ & $1,24 \mathrm{Aa}$ \\
\hline Milho + 'Piatã' + eucalipto & $52.734 \mathrm{Ba}$ & $55.078 \mathrm{Ba}$ & $2,19 \mathrm{Bb}$ & $2,27 \mathrm{Aa}$ & $1,17 \mathrm{BCb}$ & $1,23 \mathrm{Aa}$ \\
\hline Milho em monocultivo & 75.000 Aa & $75.000 \mathrm{Aa}$ & $2,30 \mathrm{Aa}$ & $2,32 \mathrm{Aa}$ & $1,24 \mathrm{Aa}$ & $1,25 \mathrm{Aa}$ \\
\hline $\mathrm{CV}$ & \multicolumn{2}{|c|}{12,45} & \multicolumn{2}{|c|}{1,79} & \multicolumn{2}{|c|}{1,85} \\
\hline
\end{tabular}

$*$ Atr + Nic $=$ Atrazine $\left(1,5 \mathrm{~kg} \mathrm{ha}^{-1}\right)+$ nicosulfuron $\left(0,006 \mathrm{~kg} \mathrm{ha}^{-1}\right)$. Médias seguidas pela mesma letra maiúscula nas colunas e minúscula nas linhas não diferem pelo teste de Tukey a $5 \%$ de probabilidade. CV: Coeficiente de variação.

GARCIA et al., 2013; FREITAS et al., 2013). Dessa maneira, a aplicação da subdose do nicossulfuron, além de controlar as plantas daninhas da família Poaceae, favoreceu o crescimento das plantas de milho, nos sistemas consorciados, pela redução da competição com as forrageiras cultivadas. Esse fato torna-se mais evidente quando se observam as características do milho em monocultivo, no qual a altura de planta e de inserção de espigas foi semelhante aos da aplicação de atrazine isolada ou em mistura no tanque com nicosulfuron (Tabela 1).

Com relação às alturas das plantas de milho e de inserção de espigas relativas aos arranjos de plantio dentro de cada manejo de planta daninha, verificaram-se diferenças com a aplicação isolada de atrazine, com maiores valores nas subparcelas com B. decumbens, independente do arranjo arbóreo, e no milho em monocultivo. No manejo de plantas daninhas com nicosulfuron, não foram observadas diferenças significativas entre os tratamentos, para a variável altura de plantas e de inserção de espigas de milho (Tabela 1).

$O$ consórcio com B. decumbens proporcionou maior altura das plantas de milho, possivelmente, devido ao menor efeito de competição desta forrageira com a cultura anual (Tabela 1). Esses resultados corroboram SEVERINO et al. (2006a), que, estudando a interferência entre a cultura do milho, espécies forrageiras e plantas daninhas em consórcio, observaram que, dentre as espécies $\boldsymbol{B}$. decumbens, $\boldsymbol{B}$. brizantha e Panicum maximum, a $B$. decumbens foi a forrageira menos eficiente quanto à habilidade de competição interespecífica, tendo menor produção de massa seca em relação as duas outras forrageiras.

Tabela 2 - Número de espigas e produtividade do milho (fileiras centrais e laterais) sob diferentes manejos de plantas daninhas e arranjos de plantio entre a cultura anual, forrageiras e espécies arbóreas.

\begin{tabular}{|c|c|c|c|c|c|c|}
\hline \multirow{3}{*}{ Arranjo de Plantio } & \multirow{2}{*}{\multicolumn{2}{|c|}{ Número espigas (espigas planta ${ }^{-1}$ ) }} & \multicolumn{4}{|c|}{---- Produção do milho $\left(\mathrm{t} \mathrm{ha}^{-1}\right)$ - } \\
\hline & & & \multicolumn{2}{|c|}{---- Fileiras centrais ------ } & \multicolumn{2}{|c|}{------ Fileiras laterais ------ } \\
\hline & Atrazine & Atr + Nic. & Atrazine & Atr + Nic. & Atrazine & Atr + Nic. \\
\hline Milho + 'Marandu' + eucalipto & $0,97^{\text {ns }}$ & $1,00^{\mathrm{ns}}$ & $5,13 \mathrm{Ba}$ & $5,63 \mathrm{Ba}$ & $5,27 \mathrm{Ba}$ & $5,72 \mathrm{Ba}$ \\
\hline Milho + 'Marandu' + eucalipto+acácia & 1,00 & 1,03 & $5,27 \mathrm{Ba}$ & $5,53 \mathrm{Ba}$ & $5,36 \mathrm{Ba}$ & $5,60 \mathrm{Ba}$ \\
\hline Milho + 'Basilisk' + eucalipto & 1,03 & 1,09 & $5,48 \mathrm{Ba}$ & $5,75 \mathrm{Ba}$ & $5,55 \mathrm{Ba}$ & $5,75 \mathrm{Ba}$ \\
\hline Milho + 'Basilisk' + eucalipto + acácia & 1,00 & 1,00 & $5,45 \mathrm{Ba}$ & $5,72 \mathrm{Ba}$ & $5,47 \mathrm{Ba}$ & $5,77 \mathrm{Ba}$ \\
\hline Milho + 'Piatã' + eucalipto & 1,00 & 1,03 & $5,40 \mathrm{Ba}$ & $5,70 \mathrm{Ba}$ & $5,48 \mathrm{Ba}$ & $5,74 \mathrm{Ba}$ \\
\hline Milho + 'Piatã' + eucalipto & 1,00 & 1,00 & $5,45 \mathrm{Ba}$ & $5,69 \mathrm{Ba}$ & $5,46 \mathrm{Ba}$ & $5,77 \mathrm{Ba}$ \\
\hline Milho em monocultivo & 1,00 & 1,06 & 7,67 Aa & 7,75 Aa & 7,72 Aa & 7,82 Aa \\
\hline $\mathrm{CV}$ & \multicolumn{2}{|c|}{1,17} & \multicolumn{2}{|c|}{8,90} & \multicolumn{2}{|c|}{10,86} \\
\hline
\end{tabular}

*Atr + Nic $=$ Atrazine $\left(1,5 \mathrm{~kg} \mathrm{ha}^{-1}\right)+$ nicosulfuron $\left(0,006 \mathrm{~kg} \mathrm{ha}^{-1}\right)$. Médias seguidas pela mesma letra maiúscula nas colunas e minúscula nas linhas não diferem pelo teste de Tukey a $5 \%$ de probabilidade. CV: Coeficiente de variação. ns: não siginificativo a $5 \%$ de probabilidade. 
Não houve diferença no número de espigas por planta em função do arranjo de plantio de espécies cultivadas no sistema agrossilvipastoril e em monocultivo, e nem em função do manejo de plantas daninhas (Tabela 1$)$. O número médio de espigas por planta de milho foi próximo de 1,0, o que é comum em cultivares melhoradas, porém que podem ser modificados em função da competição ou variações no espaçamento. Neste trabalho, a possível competição pela presença de plantas forrageiras em consórcio com o milho não influenciou essa característica. Estes resultados também demonstram que as plantas de eucalipto e acácia não influenciaram negativamente a produção de espigas de milho, provavelmente pelo fato de o plantio das espécies em consórcio ter sido na mesma época.

Os manejos de plantas daninhas não influenciaram a produtividade de grãos de milho de cada sistema (sistema agrossilvipastoril e monocultivo), tanto nas fileiras centrais quanto laterais (Tabela 2). Entretanto, a produtividade foi alterada pelos diferentes arranjos de plantio, sendo inferior no sistema agrossilvipastoril. Por sua vez, não foi observada diferença na produtividade de milho entre os arranjos de plantio no sistema agrossilvipastoril (Tabela 2). Estes resultados demonstram que as plantas de eucalipto e acácia não apresentaram efeitos negativos na produtividade de milho, nos diferentes arranjos de consórcios avaliados. Isso, possivelmente, ocorreu devido ao baixo porte das espécies arbóreas até a época da colheita do milho (médias de $1,50 \mathrm{~m}$ para eucalipto e $0,91 \mathrm{~m}$ para as plantas de acácia), além da distância de $1,5 \mathrm{~m}$ e de $5,5 \mathrm{~m}$ de cultivo das árvores às linhas laterais e centrais de milho, respectivamente. Todavia, é provável que num segundo cultivo de milho na área, no ano agrícola seguinte, o sombreamento e a competição por nutrientes e água pelo componente arbóreo possa afetar a produtividade de grãos, considerando o espaçamento utilizado.

Estes resultados estão de acordo com os reportados por DANIEL et al. (2004), que, em estudo de um sistema agroflorestal com cultivo simultâneo de eucalipto e milho em Mato Grosso do Sul até a segunda safra de milho, a altura de plantas, inserção de espigas e produtividade de milho não foram influenciados pelas árvores de eucalipto. No entanto, a partir da terceira safra de milho, estas variáveis passaram a ser modificadas pelo eucalipto, principalmente nas linhas de milho próximas às árvores. Conforme estes autores, no primeiro ano de implantação do consórcio, é recomendável que não se utilize a primeira linha de milho tão próximo da linha de eucalipto, visando a não interferência do milho sobre a espécie arbórea.

Em outro trabalho, MACEDO et al. (2006) compararam a produção média de grãos de milho cultivado em monocultivo com a produção em sistemas consorciados com clones de eucalipto com 24 meses e observaram redução na produção média nesses sistemas consorciados de 81,04, 69,69, 58,85 e 58,62\%, respectivamente, nos consórcios com os clones 137 de Eucalyptus camaldulensis, 13 de $\boldsymbol{E}$. urophylla, 180 de E. camaldulensis e 44 de $\boldsymbol{E}$. urophylla, implantados no espaçamento 10 x $4 \mathrm{~m}$. A produção média de grãos de milho, obtida nas linhas distanciada entre 1,8 e $2,7 \mathrm{~m}$ das linhas de plantio de eucalipto, apresentou redução de $29,68 \%$ em relação à produção média de grãos de milho, obtida nas linhas de plantio mais distantes das árvores de eucalipto (entre 4,5 e 5,4m de distância), provavelmente devido ao maior tempo de sombreamento nas plantas de milho localizadas mais próximas das linhas de plantio de eucalipto.

As respostas do milho ao sistema agrossilvipastoril podem variar com o híbrido utilizado. A escolha de qual híbrido depende da melhor indicação para determinada situação. No cultivo de milho consorciado com plantas forrageiras e árvores, nos sistemas agrossilvipastoris, em que se preconiza o uso da agricultura tecnificada, com grande uso de insumos e colheita mecânica, e onde se busca altos níveis de produtividade, os híbridos são recomendados por possibilitar cobrir os custos de produção e, em alguns casos, gerar renda ao produtor (MAGNAVACA \& PARENTONI, 1990; SANTOS et al, 2008). Nesse caso, o híbrido duplo por ser o mais comercializado e de menor custo, em relação ao híbrido simples e triplo, pode trazer mais vantagens ao produtor.

Ao considerar a média de produtividade de milho em monocultivo em Minas Gerais $(5.486 \mathrm{~kg}$ $\left.\mathrm{ha}^{-1}\right)$ e a média nacional $\left(5.060 \mathrm{~kg} \mathrm{ha}^{-1}\right.$ ) (IBGE, 2014), conclui-se que a produtividade nos sistemas consorciados (Tabela 2) foi satisfatória, mesmo tratando-se de área de pastagem declivosa e em condições de degradação.

\section{CONCLUSÃO}

A aplicação de nicosulfuron em mistura com atrazine contribui para aumentar a altura de plantas de milho e inserção de espigas, sem influenciar na produtividade de grãos de milho.

O eucalipto, acácia e as espécies de braquiárias, estabelecidos concomitantemente, não 
influenciam na produtividade de milho no primeiro ano de cultivo. A produtividade de grãos de milho é reduzida no sistema agrossilvipastoril em relação ao monocultivo, devido à área ocupada pelo componente arbóreo.

\section{REFERÊNCIAS}

DANIEL, O. et al. Avaliação de um sistema agroflorestal eucalipto-milho no Mato Grosso do Sul. Agrossilvicultura, v.1, n.1, p.15-28, 2004. Disponível em: <http://www.sbag.org.br/02SBAG-v1-n1-2004-15-28.pdf>. Acesso em: 22 jul. 2014.

FERREIRA, L.R. et al. Formação de pastagens em sistemas de integração. Informe Agropecuário, v.28, n.240, p.5262, 2007. Disponível em: <http://www.emater.mg.gov.br/ doc/intranet/upload/ilps/ilp\%20epamig\%20informe $\% 20$ agropecu\%C3\%A1 rio.doc>. Acesso em: 20 jul. 2014.

FREITAS, F.C.L. et al. Formação de pastagem via consórcio de Brachiaria brizantha com milho para silagem no sistema de plantio direto. Planta Daninha, v.23, n.1, p.49-58, 2005. Disponível em: $<$ http://www.scielo.br/pdf/pd/v23n1/23928.pdf>. Acesso em: 21 jul. 2014. doi: 10.1590/S0100-83582005000100007.

FREITAS, F.C.L. et al. Comportamento de cultivares de milho no consórcio com Brachiaria brizantha na presença e ausência de foramsulfuron + iodosulfuron-methyl para o manejo da forrageira. Planta Daninha, v.26, n.1, p.215-221, 2008. Disponível em: $<$ http://www.scielo.br/pdf/pd/v26n1/a22v26n1.pdf $>$. Acesso em: 22 jul. 2014. doi: 10.1590/S0100-83582008000100022.

FREITAS, M.A.M. Impacto do consórcio milho-braquiária no crescimento, características nutricionais e fisiológicas do milho e na atividade da microbiota do solo. 2013. $76 \mathrm{f}$ Tese (Doutorado em Fitotecnia) - Curso de Pós-graduação em Fitotecnia, Universidade Federal de Viçosa, MG.

GARCIA, C.M.P. et al. Desempenho agronômico da cultura do milho e espécies forrageiras em sistema de Integração Lavoura-Pecuária no Cerrado. Ciência Rural, v.43, n.44, p.589-595, 2013. Disponível em: < http://www.scielo.br/pdf/ cr/v43n4/a10413cr6763.pdf $>$. Acesso em: 26 jul. 2014. doi: 10.1590/S0103-84782013000400005.

GIMENES, M.J. et al. Interferência de espécies forrageiras em consórcio com a cultura do milho. Revista da Faculdade de Zootecnia, Veterinária e Agronomia, v.15, n.2, p.61-76, 2008. Disponível em: <http://revistaseletronicas.pucrs.br/ojs/index.php/ fzva/article/view/2804/3896>. Acesso em: 16 jul. 2014.

INSTITUTO BRASILEIRO DE GEOGRAFIA E ESTATÍSTICA (IBGE). Levantamento Sistemático Produção Agrícola Julho de 2014. Disponível em: <ftp://ftp.ibge.gov.br/Producao Agricola/Fasciculo Indicadores IBGE/estProdAgr 201407. pdf>. Acesso em: 28 jul 2014.
JAKELAITIS, A. et al. Manejo de plantas daninhas no consórcio de milho com capim braquiária (Brachiaria decumbens). Planta Daninha, v.22, n.4, p.553-560, 2004. Disponível em: <http:// www.scielo.br/pdf/pd/v22n4/a09v22n4.pdf >. Acesso em: 20 jul. 2014. doi: 10.1590/S0100-83582004000400009.

JAKELAITIS, A. et al. Influência de herbicidas e de sistemas de semeadura de Brachiaria brizantha consorciada com milho. Planta Daninha, v.2, n.1, p.59-67, 2005. Disponível em: $<$ http:// www.scielo.br/pdf/pd/v23n1/23929.pdf $>$. Acesso em: 20 jul. 2014. doi: 10.1590/S0100-83582005000100008.

MACEDO, R.L.G. et al. Desempenho silvicultural de clones de eucalipto e características agronômicas de milho cultivados em sistema silviagrícola. Revista Árvore, v.30, n.5, p.701-709, 2006. Disponível em: <http://www.scielo.br/pdf/rarv/v30n5/ a03v30n5.pdf $>$. Acesso em: 22 jul. 2014. doi: 10.1590/S010067622006000500003 .

MELOTTO, A. et al. Sobrevivência e crescimento inicial em campo de espécies florestais nativas do Brasil Central indicadas para sistemas silvipastoris. Revista Árvore, v.33, n.3, p.425432, 2009. Disponível em: <http://www.scielo.br/pdf/rarv/ v33n3/04.pdf>. Acesso em: 21 jul. 2014. doi: 10.1590/S010067622009000300004 .

PETTER, F.A. et al. Seletividade de herbicidas à cultura do milho e ao capim braquiária cultivadas no sistema de integração lavoura-pecuária. Semina: Ciências Agrárias, v.32, n.3, p.855-864, 2011. Disponível em: <http://www. uel.br/revistas/uel/index.php/semagrarias/article/view/16790359.2011v32n3p855/9042>. Acesso em: 21 jul. 2014 . doi: 10.5433/1679-0359.2011v32n3p855.

SEVERINO, F.J. et al. Interferências mútuas entre a cultura do milho, espécies forrageiras e plantas daninhas em um sistema de consórcio, II - implicações sobre as espécies forrageiras. Planta Daninha, v.24, n.1, p.45-52, 2006a. Disponível em: <http://www. scielo.br/pdf/pd/v24n1/a06v24n1.pdf>. Acesso em: 22 jul. 2014. doi: 10.1590/S0100-83582006000100006.

SEVERINO, F.J. et al. Interferências mútuas entre a cultura do milho, espécies forrageiras e plantas daninhas em um sistema de consórcio, III - implicações sobre as plantas daninhas. Planta Daninha, v.24, n.1, p.53-60, 2006b. Disponível em: <http://www. scielo.br/pdfpd/v24n1/a07v24n1.pdf>. Acesso em: 24 jul. 2014. doi: $10.1590 / \mathrm{S} 0100-83582006000100007$.

SILVA, P.I.B. et al. Crescimento e rendimento do milho e da braquiária em sistema consorciado com diferentes manejos de plantas daninhas. Planta Daninha, v.32, n.2, p.301-309, 2014. Disponível em: $<$ http://www.scielo.br/scielo.php?script=sci_arttex $\mathrm{t} \& \mathrm{pid}=\mathrm{S} 0100-83582014000200007 \& \operatorname{lng}=\mathrm{pt} \& \mathrm{nrm}=\mathrm{iso}>$. Acesso em: 15 ago. 2014. doi: 10.1590/S0100-83582014000200007. 